To eradicate tuberculosis the authors stress that we want the will to do so, the wherewithal to work and the foresight to plan for a generation ahead. The book is a summary of the knowledge required to achieve this end.

This is altogether an excellent book and is well bound, attractively printed and illustrated and can be thoroughly recommended.

\section{Normal Growth and Cancer}

By Grace Medes, Ph.D. \& S. P. ReimanN, M.D. Pp. xiv +268 illustrated. Philadelphia and Montreal : J. B. Lippincott. London: Pitman Medical. 1963. 65s.

The authors, formerly directors of research institutes in Philadelphia, have provided a printed record of their informal discussions on cancer research over the years. Their hopeful object is that the material and methods of presentation in this book will be of help to the thoughtful practicing physician. Premedical students should find it of particular use, and students in other branches of science, as well as in such fields as sociology, will find it of interest. The general public will find it an affirmative answer to the often asked question: "Is progress being made?",

No one volume could hope to fulfil all these divergent interests, and this book is no exception. Even senior medical students would not find it adequate for their purpose. In essence, it is a historical review of normal and cancerous growth, well, and often amusingly, written. Though the inclusion of references to DNA provides a sophisticated veneer, it is unfortunately out of date in many respects, particularly in the field of biochemistry and in discussing the endocrine glands.

In a book of this size, it seems unnecessary to devote a chapter to the development of optical instruments.

It is indeed a pity that the combination of a distinguished biochemist and pathologist did not result in a more comprehensive account. Within these limitations however workers outside the field will find this a stimulating review which could lead on to the study of other more authoritative works.

\section{Guide to Psychiatry}

By MYRe SiM M.D., D.P.M. Pp. ix + 868 . Edinburgh \& London: E. \& S. Livingstone. 1963. $55 \mathrm{~s}$.

The author of this new textbook has previously revealed an eclectic approach towards psychiatry together with a wide interest. These qualities are apparent in this text in which the field of psychiatry is covered in textbook fashion.

The book starts with chapters on psychology, psychopathology, genetics and cybernetics and leads on to a consideration of the neuroses, psychoses, psychosomatic medicine and sub-normality and their treatments. The final chapters are devoted to the legal aspects of psychiatry and the technique of psychiatric examination of the patient. He draws quite widely from the recent psychiatric literature and the book, as is suggested in the preface, serves as a reasonable introduction to this. To take the author up on one point, he is perhaps over-emphatic when stating that there can never be psychiatric grounds for termination of pregnancy. He seems anyway to only consider the problem relevant to puerperal psychosis. His clinical discussion of this group of illnesses is also curiously placed in the chapter on the legal aspects of psychiatry.

The text is always easy to read and the approach is generally sufficiently critical to make it of value? to the uninitated. This is a useful addition to the field of textbooks of psychiatry aimed at both? undergraduates and graduates.

\section{Cancer Progress 1963}

Edited by R. W. RAVEN, O.B.E., (Mil) T.D., F.R.C.S. $\frac{\bar{\rho}}{\bar{\rho}}$ Pp. xii + 254 illustrated. London: Butterworths. 1963. 60s.

To anyone interested in trends in the biologicalos approach to cancer, this book makes fascinatingreading. In line with current practice in "recent progress" series, it consists of a collection of essays on specific aspects of cancer research, epidemiology, diagnosis, and treatment; by authorities fromò both sides of the Atlantic.

At a time when radiotherapeutic methods are? undergoing critical reappraisal, the chapters on the effects of radiotherapy on normal tissues, of dose time relationships in radiotherapeutic treatment, ando experiments modifying the effects of radiotherapy are particularly interesting. Other excellent reviewser cover viruses and cancer, advances in chemothe-po raphy, cancer cells in the circulating blood, Burkitt's malignant lymphoma of African children, and the use of R.N.A. and D.N.A. estimations incancer diagnosis.

The style is necessarily terse, the production excellent, and it is liberally supplied with references (there are over 600 on viruses and cancer alone).3 Some might find such profusion bewildering and wish for guidance to key papers.

Mr. Raven is to be congratulated on his chotce of material, and presentation in a stimulating volumes which will be widely appreciated by all engaged In the diagnosis and treatment of cancer.

\section{General Palhology}

J. B. WALTER, M.D., M.R.C.P., and M. S. ISRAEL M.B., M.R.C.P., D.C.P. Pp. xii + 937, illustrated

London: J. \& A. Churchill. 1963. 100s.

Candidates for the Primary F.R.C.S. and F.F.A. examinations should be particularly grateful to the authors who are both on the staff of the Institute of Basic Medical Sciences at the Royal College of Surgeons of England. However the subject is ap proached from the angle that will appeal to alf. clinicians whose knowledge of pathology, acquiredo midway through their student life, is rusty? Throughout the book recent advances have beeno given suitable prominence and their sighificance correlated with the main body of knowledge The standard is high throughout, but chapters on heart failure, renal failure and hepatic failure are specially welcome. The scope of the book is remarkably broad and there are sections on topics not always found in textbooks of pathology, such as Hospital Infection, Antibacterial Chemotherapy and four chapters on blood diseases and transfusion $N$ Bacteriology is given cursory attention essentially from the point of view of revision, which renders 0 the book less valuable to a reader making his firs acquaintaince with the subject. The style is lucid and the book well illustrated with useful diagramse as well as microphotographs and pictures of pathoo logical specimens. Dr. Walter and Dr. Israel are tō be congratulated on their achievement in producings? a book no doubt destined to become a standard work. 